\title{
Enhanced calcium ion mobilization in osteoblasts on amino group containing plasma polymer nanolayer
}

\author{
Susanne Staehlke ${ }^{1}$, Henrike Rebl ${ }^{1}$, Birgit Finke ${ }^{2}$, Petra Mueller ${ }^{1}$, Martina Gruening ${ }^{1}$ and J. Barbara Nebe ${ }^{*^{*} \text { (i) }}$
}

\begin{abstract}
Background: Biomaterial modifications_chemical and topographical—are of particular importance for the integration of materials in biosystems. Cells are known to sense these biomaterial characteristics, but it has remained unclear which physiological processes bio modifications trigger. Hence, the question arises of whether the dynamic of intracellular calcium ions is important for the characterization of the cell-material interaction. In our prior research we could demonstrate that a defined geometrical surface topography affects the cell physiology; this was finally detectable in a reduced intracellular calcium mobilization after the addition of adenosine triphosphate (ATP).
\end{abstract}

Results: This new contribution examines the cell physiology of human osteoblasts concerning the relative cell viability and the calcium ion dynamic on different chemical modifications of silicon-titanium (Ti) substrates. Chemical modifications comprising the coating of Ti surfaces with a plasma polymerized allylamine (PPAAm)-layer or with a thin layer of collagen type-I were compared with a bare Ti substrate as well as tissue culture plastic. For this purpose, the human osteoblasts (MG-63 and primary osteoblasts) were seeded onto the surfaces for $24 \mathrm{~h}$. The relative cell viability was determined by colorimetric measurements of the cell metabolism and relativized to the density of cells quantified using crystal violet staining. The calcium ion dynamic of osteoblasts was evaluated by the calcium imaging analysis of fluo-3 stained vital cells using a confocal laser scanning microscope. The positively charged nano PPAAm-layer resulted in enhanced intracellular calcium ion mobilization after ATP-stimulus and cell viability. This study underlines the importance of the calcium signaling for the manifestation of the cell physiology.

Conclusions: Our current work provides new insights into the intracellular calcium dynamic caused by diverse chemical surface compositions. The calcium ion dynamic appears to be a sensitive parameter for the cell physiology and, thus, may represent a useful approach for evaluating a new biomaterial. In this regard, reliable in vitro-tests of cell behavior at the interface to a material are crucial steps in securing the success of a new biomaterial in medicine.

Keywords: Chemical surface modifications, Titanium, Plasma polymer, Tissue culture plastic, Collagen type-I, Human osteoblasts, Zeta potential, Cell viability, Signaling, Calcium ion dynamic

\section{Background}

Nowadays, there is an increasing demand for permanent, temporary and biodegradable orthopedic devices developed for bone repair and regeneration [1-3]. The cellbiomaterial interaction is a major challenge for tissue

\footnotetext{
*Correspondence: barbara.nebe@med.uni-rostock.de

1 Dept. of Cell Biology, University Medical Center Rostock, Schillingallee 69, 18057 Rostock, Germany

Full list of author information is available at the end of the article
}

engineering. Both the topographical and chemical surface stimuli of the biomaterials can affect cellular behavior, either detrimentally or favorably, at the interface [4-7]. The physico-chemical stimuli of biomaterial surfaces control complex molecular mechanisms responsible for cell function $[4,8-10]$ by mechanotransductiontranslating external signals and forces into intracellular biochemical signals [1]. As a result, initial processes like cell adhesion $[8,11]$, spreading $[9,12]$ and the mechanical attachment of cells to the biomaterial surface [5] 
further influence other cell activities such as proliferation, differentiation [2] and intracellular signaling $[4,10]$. There is limited information on whether altered cellular responses by external mechanical stimuli affect intracellular signal transmission via an intracellular calcium ion dynamic. Many cellular functions, like proliferation or differentiation, are regulated by changes of cytosolic free calcium ions $\left(\mathrm{Ca}^{2+}\right)$ [13-15]. The cations $\left(\mathrm{Ca}^{2+}\right)$ act like common intracellular signaling molecules, which function as a "second messenger" $[14,16,17]$. Cytosolic free $\mathrm{Ca}^{2+}$-concentration $\left(10^{-7} \mathrm{M}\right)$ is strictly regulated [16]. A short-term rise of $\mathrm{Ca}^{2+}$ is important for signal transmission, and intracellular calcium dynamic is triggered by a variety of factors like adenosine triphosphate (ATP) [14, $17,18]$ or mechanical forces $[10,13]$. The ligand ATP typically activates the cell-surface $G$ protein-coupled receptor (GPCR) which generates inositol-1,4,5-triphosphate (IP3); this induces transient and rapid $\mathrm{Ca}^{2+}$-release through activation of its receptor which is located in the membrane of the internal $\mathrm{Ca}^{2+}$-store, the smooth endoplasmic reticulum (ER) $[14,15,19]$. Intracellular $\mathrm{Ca}^{2+}$ as a second messenger system is responsible for signal transduction [14] e.g. the transmission of external signals and forces in adaptation to the changed environment [10, 18]. So, external signals provide a distinct $\mathrm{Ca}^{2+}$ dynamic that selectively controls long-term cellular responses like proliferation [20] and differentiation [10, 14, 15] by, e.g. binding and activation of other downstream signal proteins and transcription factors $[13,17,19]$. To study the role of the intracellular $\mathrm{Ca}^{2+}$ dynamic on different chemical surface compositions, osteoblasts were stained with a very common non-ratiometric (single wavelength) $\mathrm{Ca}^{2+}$ indicator fluo-3 $[16,21]$ and analyzed using confocal laser scanning microscopy. The variation of fluorescence intensity in vital fluo-3-labeled osteoblasts was recorded over the time of 240 cycles of $2 \mathrm{~s}$ each [10]. To stimulate the intracellular calcium dynamic, ATP was added after the 90th cycle [10].

The complex interplay between modified biomaterials and cell behavior has not yet been fully understood and elucidated. Therefore, it is important to determine parameters that reflect the cell physiological behavior of the cells in interaction with the physico-chemical properties of the biomaterial surface. Titanium (Ti) or titanium alloys (like Ti6Al4V) as implant materials in medicine fulfill highly demanding biological conditions, being both inert and biocompatible, having excellent mechanical and physical properties, and being corrosion-resistant [2]. A layer of titanium dioxide $\left(\mathrm{TiO}_{2}\right)$ forms spontaneously when titanium is exposed to air [22]. For an improved interaction of cells on titanium materials, surfaces were endowed with modified chemical as well as physical properties $[5,7$, 23]. It is known that cells sense and respond sensitively to the topographical features of surfaces [4]. In this regard, Staehlke et al. [10] found out that osteoblasts on Ti microstructures with impaired cell physiology (cell growth, actin cytoskeleton organization and synthesis of fibronectin) showed significantly reduced intracellular calcium mobilization compared to planar controls. To create new bioactive materials, in addition to the topographic modification, chemical surface properties are of significance for the cell substrate interface $[24,25]$. It is reported that the ideal cell adhesion is mediated by positively charged as well as hydrophilic surfaces [2]. The allylamine, polymerized by a low-pressure physical plasma process, generates positively charged amino groups on the wet surface $[8,11]$. The advantage of positively charged surfaces is the adsorption of molecules and proteins which mediate cell adhesion [2]. It has been shown that a PPAAm coating causes osteoblasts to respond with, in addition to improved adhesion and increased spreading [7-9], also an improved organization of the actin cytoskeleton with typically long stress fibers and enhanced focal adhesion kinase (FAK) protein expression [11, 12] which finally enhanced cell function [26]. Collagen type-I is one main organic part of the extracellular matrix (ECM), e.g. in skeletal [27] and dental bone [22]. Collagen functions as a ligand for cell adhesion receptors like integrins $[6,10]$ and is therefore a cell-attractive surface [22]. Collagen type-I layer as a biochemical surface modification supports the cell physiology, including adhesion and differentiation $[27,28]$. The objectives of this in vitro-study on human osteoblasts was to investigate the cell physiological effects of two chemically modified Ti surfacesPPAAm and collagen type-I-compared with a bare Ti substrate, as well as with standard tissue culture plastic (ibiTreat, IBIDI) (see Fig. 1). The zeta potentials on these different chemical compositions of the surface modifications were determined in order to analyze the influence of the surface charge on the cell behavior. Furthermore, this study focused on the intracellular calcium ion dynamic with its importance in the regulation of cell physiology. We have identified the intracellular calcium ion mobilization as a sensitive parameter to observe the cellular behavior on different biomaterials. Reliable in vitro-tests

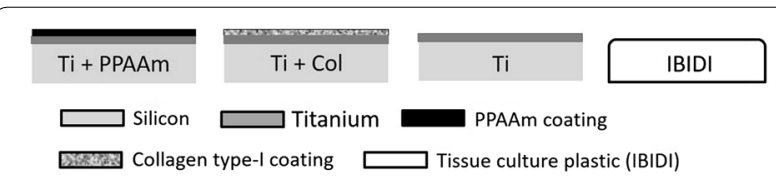

Fig. 1 Scheme of the chemical surface composition. The silicon-titanium (Ti) substrates were modified by amino functionalization with plasma polymerized allylamine (Ti+PPAAm) as well as immobilization of a bioactive collagen type-l layer $(\mathrm{Ti}+\mathrm{Col})$. These modifications were compared with bare Ti substrates and tissue culture plastic $(|B| D \mid)$ 
for the description of cell-material interactions are the precondition for the design of new biomaterial surfaces in medicine.

\section{Results}

Surface characterization reveals a positive surface charge on the PPAAm-nanolayer

In order to evaluate the existing surface charges of the different chemical surface compositions, the zeta potential at $\mathrm{pH}$ 6.0-8.0 was determined (Fig. 2). Table 1 represents the values of the zeta potential at the cell physiological $\mathrm{pH} 7.4$ [7]. These results indicated that only the PPAAm coating on $\mathrm{Ti}(\mathrm{Ti}+$ PPAAm) exhibits a positive surface charge. In contrast, the immobilized collagen type-I layer on $\mathrm{Ti}(\mathrm{Ti}+\mathrm{Col})$ revealed a slight negative surface charge, and $\mathrm{Ti}$ as well as the tissue culture plastic (IBIDI) surfaces showed a strong negative zeta potential (Table 1).

The measurements of water contact angle (WCA, distilled water) indicated that all chemical surface compositions $\left(\mathrm{Ti}+\mathrm{PPAAm}, 68.4^{\circ} ; \mathrm{Ti}+\mathrm{Col}, 60.8^{\circ}\right)$ as well as the IBIDI $\left(72.8^{\circ}\right)$ were more hydrophilic compared with $\mathrm{Ti}$ $\left(85^{\circ}\right)$ (Table 1$)$.

\section{The positively charged PPAAm nanolayer displayed} increased relative cell viability

The relative cell viability after $24 \mathrm{~h}$ was confirmed by colorimetric measurements of the cell metabolism (MTS)
Table 1 Water contact angle and zeta potential (mean \pm s.e.m.)

\begin{tabular}{lll}
\hline Surface & Water contact angle (in ${ }^{\circ}$ ) & $\begin{array}{l}\text { Zeta potential at } \mathbf{~ p H ~ 7 . 4} \\
\text { (in } \mathbf{~} \mathbf{~} \text { ) }\end{array}$ \\
\hline $\mathrm{Ti}$ & $85.0 \pm 0.7$ & $-82.3 \pm 3.9[7]$ \\
$\mathrm{Ti}+\mathrm{PPAAm}$ & $68.4 \pm 1.7$ & $+8.6 \pm 1.4[7]$ \\
$\mathrm{Ti}+\mathrm{Col}$ & $60.8 \pm 2.2$ & $-18.5 \pm 3.2[7]$ \\
$\mathrm{IBIDI}$ & $72.8 \pm 1.6$ & $-81.7 \pm 2.5$ \\
\hline
\end{tabular}

and relativized to the density of cells (crystal violet staining). We found a significantly higher relative cell viability of MG-63 cells on Ti + PPAAm $(3.66 \pm 0.27)$ in contrast to all negatively charged surfaces after $24 \mathrm{~h}$. A similar cell viability per cell number could be observed for $\mathrm{Ti}+\mathrm{Col}$ $(2.91 \pm 0.24), \mathrm{Ti}(3.08 \pm 0.18)$ and IBIDI $(2.87 \pm 0.47)$ (Fig. 3).

\section{The positively charged PPAAm nanolayer triggered an enhanced intracellular $\mathrm{Ca}^{2+}$ dynamic in MG-63 osteoblasts and $\mathrm{HOB}$}

Fluorescence measurements of vital fluo-3/acetoxymethyl ester (AM)-stained osteoblasts were recorded on the confocal laser scanning microscope (LSM780). The mean fluorescence intensity (MFI) of 10 defined regions of the cells (one region per cell, see Fig. 4) was analyzed

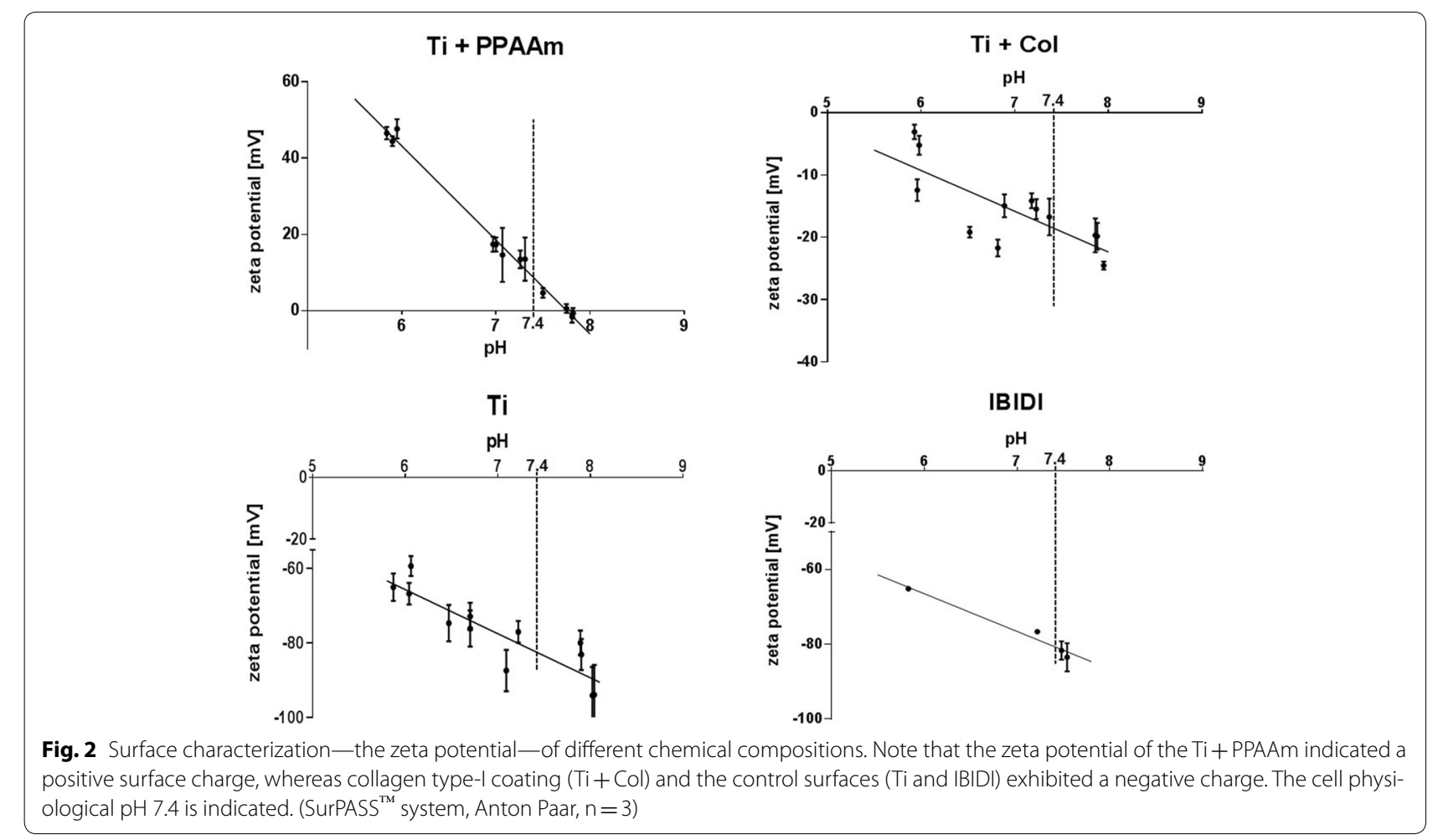




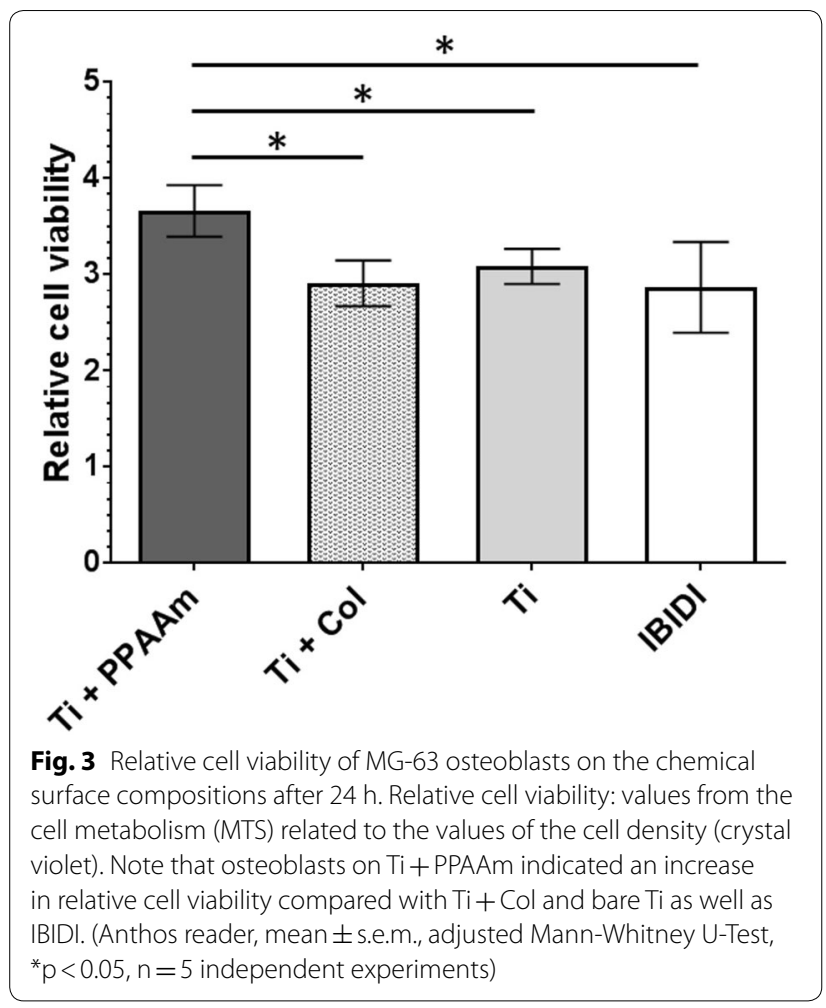

per cycle over a time series $(240$ cycles every $2 \mathrm{~s}$, total $480 \mathrm{~s}$ ). To stimulate the cytoplasmic $\mathrm{Ca}^{2+}$ rise from the endoplasmic reticulum (ER), ATP was added after the 90th cycle (180 s). The recorded fluorescence signal of the stained cells over time was evaluated as a (i) basal calcium level (without ATP stimulation, 0-180 s), and (ii) the calcium ion mobilization (after ATP stimulation, 182-480 s). The individual values can be found in Table 2. MG-63 cells on Ti + PPAAm showed a significantly increased intracellular $\mathrm{Ca}^{2+}$-mobilization after stimulation with ATP in contrast to $\mathrm{Ti}+\mathrm{Col}$, Ti and IBIDI (Fig. 5). The results indicated that the $\mathrm{Ca}^{2+}$ dynamic in MG-63 osteoblasts was influenced by a positively charged surface.

It has often been discussed that the tumor cell lines (e.g. the MG-63 cells) are different in its sensitivity to primary cells.

In order to confirm the influence of chemical modifications on intracellular $\mathrm{Ca}^{2+}$ signaling also in human primary osteoblasts $(\mathrm{HOB})$, experiments were done in direct comparison. MG-63 and HOB cells were cultured for $24 \mathrm{~h}$ only on the most noticeable chemical modification, the positively charged $\mathrm{Ti}+$ PPAAm, compared with bare Ti. The fluorescence intensity of these fluo-3-stained osteoblasts at the 120th cycle was higher in both $\mathrm{HOB}$ and MG-63 cells on Ti + PPAAm (Fig. 6a). A significantly increased cytosolic free $\mathrm{Ca}^{2+}$ mobilization after ATP stimulation was found in $\mathrm{HOB}$ as well as in MG-63 cells on $\mathrm{Ti}+$ PPAAm compared with Ti (Fig. 6b, c). The fluorescence signals are indicated in Table 3. Thus, the primary osteoblasts confirm increased calcium signaling on $\mathrm{Ti}+$ PPAAm .

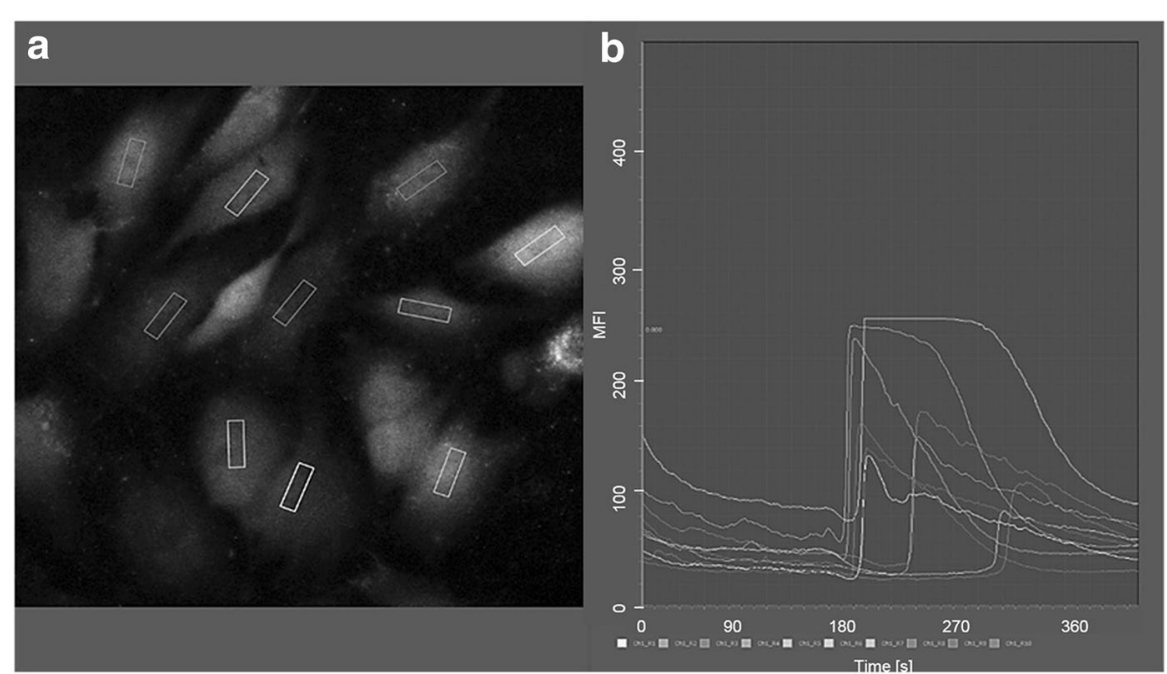

Fig. 4 Fluorescence intensity of the $\mathrm{Ca}^{2+}$ mobilization in osteoblasts over a time series using confocal laser scanning microscopy (LSM780, Carl Zeiss) and the software ZEN2 (blue edition, Carl Zeiss) in the mode "mean region of interest (ROI)". a In the first fluorescence image of the time series, the defined areas in 10 cells (one area per cell) are fixed. $\mathbf{b}$ Graphical representation of the mean fluorescence intensity (MFI) of the 10 defined areas over the entire time series 
Table 2 Mean fluorescence intensity of mobilized $\mathrm{Ca}^{2+}$ in MG-63 cells on Ti substrates (mean \pm s.e.m.)

\begin{tabular}{lllll}
\hline $\mathbf{C a}^{2+}$ signal & $\mathbf{T i}$ & $\mathbf{T i}+$ PPAAm & $\mathbf{T i}+\mathbf{C o l}$ & IBIDI \\
\hline Basal level (0-180 s) & $38.7 \pm 0.8$ & $51.9 \pm 0.6$ & $38.6 \pm 0.2$ & $23.6 \pm 0.8$ \\
After ATP (182-480 s) & $49.9 \pm 1.1$ & $89.1 \pm 1.9$ & $44.8 \pm 1.6$ & $17.2 \pm 0.1$ \\
\hline
\end{tabular}

\section{Discussion}

In the present study, osteoblast behavior (viability and calcium signaling) was correlated to different chemical surface compositions on titanium-plasma polymerized allylamine ( $\mathrm{Ti}+$ PPAAm) and a collagen type-I coating $(\mathrm{Ti}+\mathrm{Col})-i n$ comparison with the bare substrate (Ti) and tissue culture plastic (IBIDI). Using in vitro approaches, we showed clearly that chemical surface modifications of biomaterials affect the relative cell viability and, further, the intracellular $\mathrm{Ca}^{2+}$ dynamic in osteoblasts. In addition, we found a biological analysis method-calcium imaging-to determine cell regulatory mechanisms which reflect the cell behavior on different materials.

Titanium is the biomaterial of choice in medical devices due to its mechanical and biological compatibility $[22,28]$. Today, new biomaterials in medicine should be biocompatible and furthermore actively promote cellular functions [2]. Bioactive material surfaces are developed by physico-chemical modification for better osseointegration [4]. Different studies investigated the influence of surface modifications on cell-material interaction [4, 5]. The research and evaluation of new materials requires additional in vitro tests, also for the assessment of signal transduction.

The interaction between materials and osteoblasts is dependent on surface characteristics like wettability, surface charge or surface energy [3]. First of all, we analyzed the surface charge (at pH 7.4) of the different chemical compositions [7]. The zeta potential is of importance for biological responses like adhesion and spreading $[4,8,9]$. The zeta potential of surfaces modified with a $\mathrm{Ti}+$ PPAAm showed the only positive surface charge of all surfaces used in the study. The other chemical titanium modification $\mathrm{Ti}+\mathrm{Col}$ indicated a slight negative surface charge. Our comparative surfaces-bare Ti substrate as well as IBIDI-revealed a highly negative zeta potential [7].

Previous studies, which characterized the PPAAm coating, examined the positive zeta potential in addition to hydrophilicity of this nanolayer $[8,11]$. Interestingly, a greater hydrophilic potential was also observed for a collagen type-I coating, but in contrast to the PPAAmnanolayer, a negative surface charge was measured [7]. Rebl et al. [9] reported a negative surface charge for a

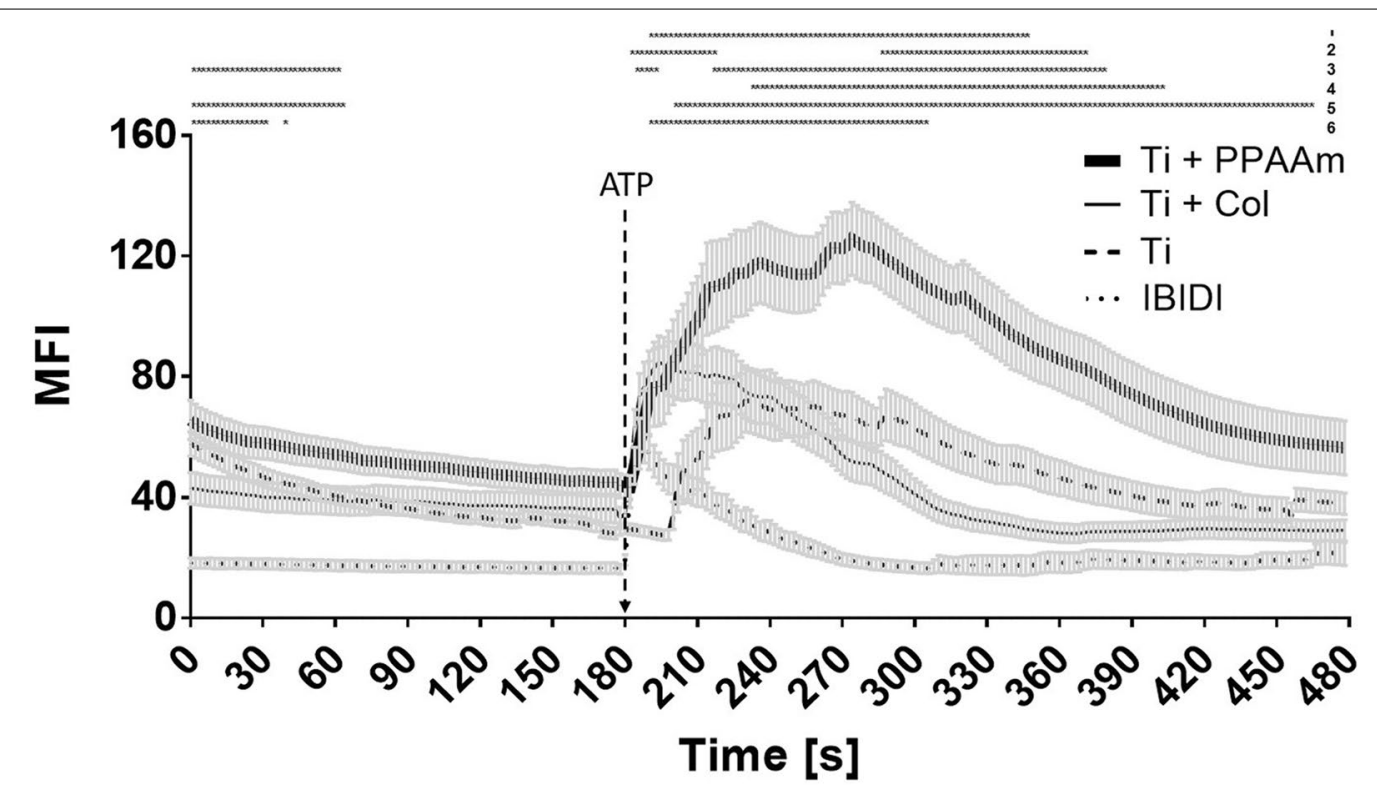

Fig. 5 Time courses of $\mathrm{Ca}^{2+}$-fluorescence signals of vital fluo-3 loaded MG-63 cells growing on different chemical surface compositions. The addition of ATP is highlighted at the time point $180 \mathrm{~s}$ (90th cycle). Note that cells on Ti + PPAAm showed significantly increased intracellular calcium signals after ATP stimulation. Cells on the control IBIDI indicated not only a weaker basal calcium signal (without ATP) but also a significantly weaker calcium ion mobilization after ATP compared with osteoblasts on Ti, Ti + PPAAm, and Ti + Col. (LSM780, Carl Zeiss; 3 independent approaches for 10 defined areas each of 10 cells per time point, polygon line as the mean \pm s.e.m., multiple t-test, $\left.{ }^{*} p<0.05\right)$. Explanations: $1=\mathrm{Ti} v \mathrm{vs}$. Ti $+\mathrm{PPAAm}, 2=\mathrm{Ti}$ vs. $\mathrm{Ti}+\mathrm{Col}, 3=\mathrm{Ti}$ vs. IBIDI, $4=\mathrm{Ti}+\mathrm{PPAAm}$ vs. Ti $+\mathrm{Col}, 5=\mathrm{Ti}+\mathrm{PPAAm}$ vs. IBIDI, $6=\mathrm{Ti}+\mathrm{Col}$ vs. IBIDI 

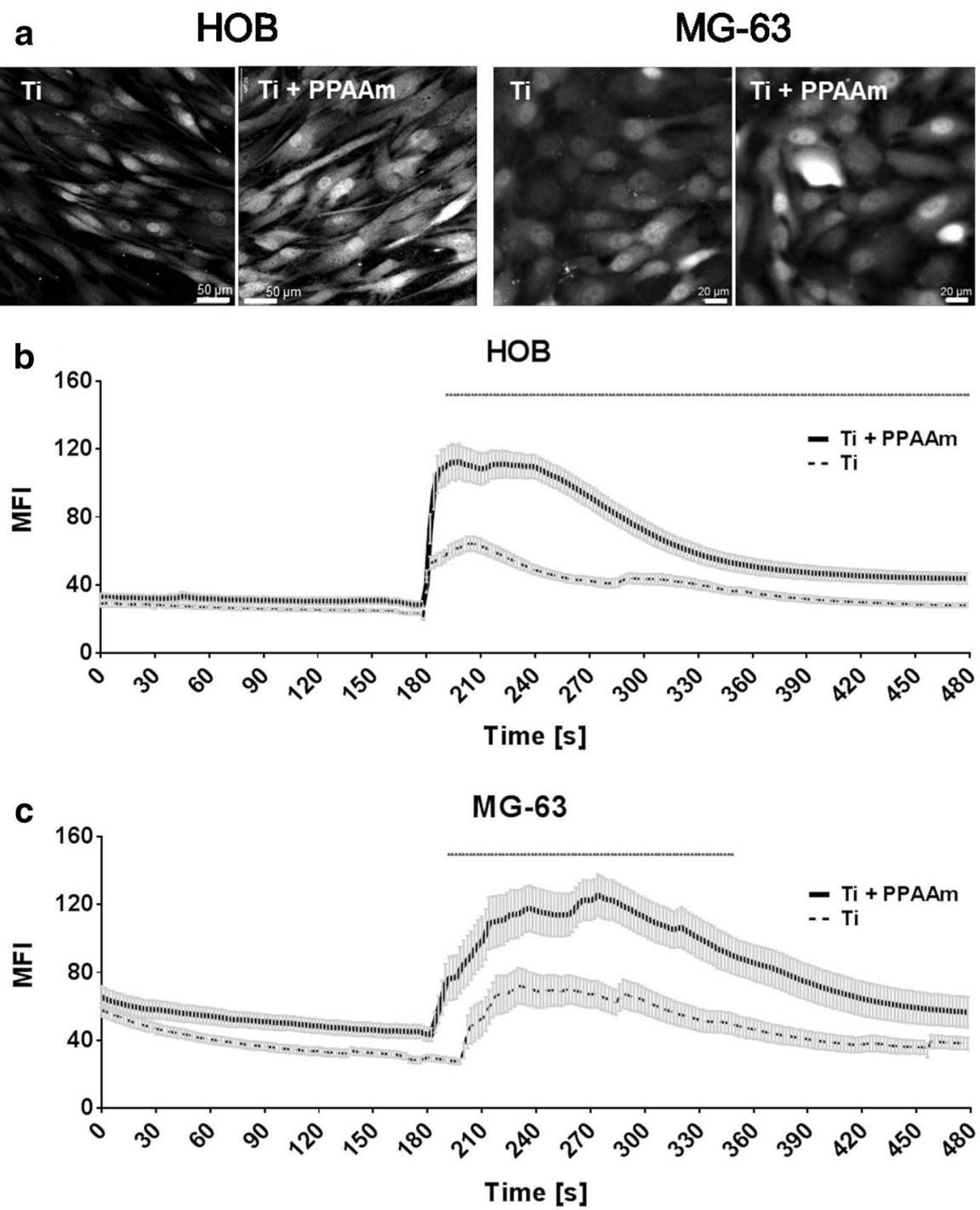

Fig. 6 Calcium imaging in vital fluo-3 loaded human osteoblasts—cell line (MG-63) and primary osteoblasts (HOB). Changes in fluorescence intensities of the cells were detected using confocal laser scanning microscopy (LSM780, Carl Zeiss, ZEN-software). a The representative fluorescence images, after ATP stimulation ( $240 \mathrm{~s}=120$ th cycle), show the $\mathrm{Ca}^{2+}$ increase on Ti+ PPAAm surfaces compared with bare Ti in MG-63 as well as HOB cells. (Scale bar MG-63: $20 \mu$ m, HOB: $50 \mu \mathrm{m}$ ). b Intracellular Ca ${ }^{2+}$ dynamics in vital primary osteoblasts (HOB) over $480 \mathrm{~s}$ (=240 cycles) every $2 \mathrm{~s}$ on $\mathrm{Ti}+$ PPAAm compared with Ti. Note the significantly enhanced intracellular calcium ion signal in HOB cells after ATP stimulus (180 s) on Ti + PPAAm. c Intracellular $\mathrm{Ca}^{2+}$ signal of MG-63 cells over time on Ti+PPAAm compared with Ti. Significant differences in the intracellular $\mathrm{Ca}^{2+}$ dynamic of MG-63 after ATP stimulation was detectable (see explanation in b). MG-63 and HOB established the same cellular reactivity in calcium signaling on $\mathrm{Ti}+$ PPAAm and bare Ti. (MG-63=3, and $\mathrm{HOB}=5$ independent approaches each for 10 defined areas of 10 cells per time point, 240 cycles, polygon line as mean \pm s.e.m., multiple t-test, $\left.{ }^{*} p<0.05\right)$

collagen type-I layer on glass as well. Likewise, IBIDI dishes, with their high negative charge, exhibit hydrophilic properties [29]. It is known that biomaterial surfaces with moderate hydrophilicity improve cell growth and biocompatibility [2]. In addition, improved initial cell adhesion on positively charged surfaces was previously observed [7-9]. The extracellular matrix (ECM) molecules, which are synthesized by osteoblasts and important for cell adhesion and regeneration [22], are negatively charged, e.g. hyaluronan or collagen type-I [12]. The collagen type-I is, on the basis of the abundant presence in human tissue, the stability and as part of the ECM, a potential, organic bioactive coating for titanium surfaces [22]. The positively charged PPAAm nanolayer is capable of attracting negatively charged biomolecules of the ECM [12], and therefore particularly suitable as a 
Table 3 Comparison of $\mathrm{Ca}^{2+}$ signals in HOB and MG-63 cells on Ti and Ti + PPAAm (mean \pm s.e.m.)

\begin{tabular}{|c|c|c|c|c|}
\hline \multirow[t]{2}{*}{$\mathrm{Ca}^{2+}$ signal } & \multicolumn{2}{|c|}{$\begin{array}{l}\text { Primary osteoblasts- } \\
\text { HOB }\end{array}$} & \multicolumn{2}{|c|}{$\begin{array}{l}\text { Osteoblast cell line- } \\
\text { MG-63 }\end{array}$} \\
\hline & $\mathrm{Ti}$ & $\mathrm{Ti}+\mathrm{PPAAm}$ & $\mathrm{Ti}$ & $\mathrm{Ti}+\mathrm{PPAAm}$ \\
\hline Basal level (0-180 s) & $26.3 \pm 0.3$ & $31.2 \pm 0.1$ & $38.7 \pm 0.8$ & $51.9 \pm 0.6$ \\
\hline $\begin{array}{l}\text { ATP peak maximum } \\
(182-300 \mathrm{~s})\end{array}$ & $50.5 \pm 1.0$ & $99.2 \pm 1.7^{*}$ & $59.3 \pm 1.9$ & $106.6 \pm 2.5^{*}$ \\
\hline $\begin{array}{l}\text { Slope after ATP } \\
\quad(302-480 \mathrm{~s})\end{array}$ & $33.4 \pm 0.5$ & $50.3 \pm 0.8^{*}$ & $43.8 \pm 0.8$ & $77.8 \pm 1.8$ \\
\hline
\end{tabular}

* Statistically significant, $\mathrm{p}<0.05$, multiple $t$-test

coating for biofunctionalized implant surfaces. Anselme et al. [4] described the electric charge, existing at the interface of biomaterials, as a significant factor in protein adsorption and integrin binding. It is postulated that for the best cell attachment a positively charged surface should be used, since cell adhesion and spreading are influenced by chemical composition and surface potential [2]. The initial cell reaction controls further cellular responses like signaling events and finally cell viability [2]. Major regulators of cell viability and proliferation are cell adhesion and cell spreading [5]. Prior investigations on surfaces coated with PPAAm indicated a significant increase in initial osteoblast adhesion and spreading $[9,11,12]$, and thus an enhanced cell-material contact which finally improved the proliferation rate [26]. The positively charged modification with a nanolayer of PPAAm seems to be attractive for cells and stabilizes the adhesion of cells on the biomaterial surface, resulting, in addition, in better implant osseointegration $[8,12,26]$.

The new findings of this study confirm this assumption. In this study, osteoblasts which were cultured for $24 \mathrm{~h}$ on surfaces with a positively charged PPAAm nanolayer showed a significant increase of relative cell viability compared with negatively charged surfaces. Cell viability on $\mathrm{Ti}+\mathrm{Col}$ appears to be unchanged compared with the $\mathrm{Ti}$ and IBIDI. It is postulated in the literature that a bioactive protein coating with collagen type-I acts as a ligand for cell adhesion receptors $[4,6]$ and therefore will be a cell attractive surface [25]. In this regard, in in vitro- and in vivo-studies Avila et al. [22] presented enhanced cellular behavior on collagen type-I coated implants. Also, in long-term experiments (8 weeks) Sverzut et al. [25] showed that collagen type-I coatings led to improved osseointegration and differentiation in vivo. In the proximal tibial metaphysis of rats, Reyes et al. [30] compared bone-to-implant contact of machined titanium surfaces (Ti) with e.g. bovine type I collagen (Col I). After 4 weeks of healing the mean bone-to-implant contact percentages were $58 \%$ for Col I and $43 \%$ for Ti. Col I was statistically higher compared with $\mathrm{Ti}$. The authors concluded that $\mathrm{Col}$ I enhanced bone repair and implant integration.
Further literature showed inconsistent results in in vitro approaches. Also, Morra et al. [28] postulated that the osteoblast growth rate on collagen-modified biomaterials is lower and cell viability is similar compared with pure titanium. Regarding our study, Rebl et al. [9] were also able to show that the positive charges of a PPAAm coating enhanced the cell physiology (initial cell adhesion and spreading), and were more effective than the collagen type-I coated surfaces. Thus, the zeta potential seems to be an important surface characteristic for cell physiology, as demonstrated in this study with the relative cell viability.

This feature of cell physiology-relative cell viability-is also reflected in the intracellular calcium dynamic after stimulation with ATP. In this study, an adapted cytosolic calcium signal was found corresponding to the relative cell viability in MG-63 osteoblasts on the different chemical compositions. It is known from the literature that intracellular $\mathrm{Ca}^{2+}$ is a component of downstream signaling cascades $[13,14,17]$ and regulates characteristics of cell physiology such as proliferation $[15,20]$. The analysis of the intracellular $\mathrm{Ca}^{2+}$ dynamic in fluo-3 stained osteoblasts on different chemical surface compositions presented here were performed using confocal laser scanning microscopy. The fluorescence changes over the time of 240 cycles were recorded every $2 \mathrm{~s}$ and evaluated. The basal calcium level (without stimulation), and the calcium dynamic after stimulation with ATP (even at the 90th cycle) were determined [10]. Interestingly, the cells on positively charged PPAAm reacted with a significantly higher calcium signal after ATP-stimulus compared with cells on negatively charged surfaces. Some studies showed a similar cellular reaction of the cell line MG-63 and primary osteoblasts (HOB) on biomaterials concerning the expression of integrin subunits and signaling, and declared MG-63 cells to be useful in in vitro models [31]. Nevertheless, they intend to verify appropriate functional studies with human primary cells [31]. Therefore, we placed $\mathrm{HOB}$ on the most noticeable chemical modification ( $\mathrm{Ti}+$ PPAAm) compared with bare $\mathrm{Ti}$ and analyzed the intracellular calcium signal. Not only in the MG-63 cell line, but also in $\mathrm{HOB}$, we were able to demonstrate this phenomenon of increased $\mathrm{Ca}^{2+}$ mobilization on $\mathrm{Ti}+$ PPAAm. Also, Ravenscroft et al. [24] showed that chemical surface features of self-assembled monolayers on coverslips (DETA) can influence the calcium dynamic after an electrical stimulation $(1 \mathrm{HZ}, 6 \mathrm{~V}$ signal, $5 \mathrm{~ms}$ per pulse), as demonstrated with fura 2-stained chicken embryonic cardiac myocytes. Cells on the hydrophilic silanes showed a significant higher excitation-induced $\mathrm{Ca}^{2+}$ concentration and dynamic (i.e. calcium transients, amplitude and duration). 
Due to good spreading and adhesion properties, adhesion receptors such as integrins mediated stronger calcium signals [13]. Furthermore, cytoskeletal organization and formation of a cytoskeletal signaling complex affects the intracellular calcium mobilization [13]. In previous studies it was found that osteoblasts grown on the PPAAm nanolayer displayed improved osteoblast adhesion and spreading as well as a strong actin filament network $[11,12]$. This new, further study shows accordingly the significantly increased calcium ion dynamic in osteoblasts on this positively charged surface.

In another earlier study we indicated altered cellular behavior on the topography of a defined micro-structured surface (micro pillars): changed actin organization resulting in short fiber formation on the top of the pillars [10] and, as a consequence, a significant decrease in the intracellular calcium signal $[10,16]$. These topographydependent reactions finally led to inhibited cell function [10]. Thus, we suggest that osteoblasts transmitted external signals and forces from the environment into the cell via calcium signaling. The stringent regulation of the intracellular $\mathrm{Ca}^{2+}$ dynamic plays an important role in cell function $[10,13,15]$. It seems to be a correlation between the increased viability of MG-63 cells and the enhanced calcium ion dynamic detected on Ti+PPAAm. In this regard, it has been shown that the intracellular $\mathrm{Ca}^{2+}$ dynamic plays an important role, and thus can be an indicator for the behavior of cells on different biomaterials.

\section{Conclusion}

The material surface functionalization with positively charged plasma-polymerized allylamine (PPAAm) resulted in increased cell viability and, furthermore, in an enhanced calcium ion mobilization after ATP stimulation. We conclude that the calcium ion dynamic reflects the behavior of the cells on different surfaces accordingly. To develop new biomaterials it is of importance to understand the interaction of cells with the underlying material.

We have found an in vitro-method-calcium imaging-to assess the cell response to functionalized surface modifications. This study is one of the first to examine the intracellular calcium ion level and stimulus-dependent dynamic of intracellular calcium ions on chemically different coatings. These new results support our hypothesis that the calcium ion dynamic in cells is important in the transmission of external signals into the cell, which finally regulate the cell physiology.

\section{Methods}

\section{Surfaces and chemical composition}

The bare substrate was silicon with a final $100 \mathrm{~nm}$ titanium (Ti) coating. The surfaces thus had a native titanium-oxide layer $\left(\mathrm{TiO}_{2}\right)$ at which the cells interact. The Ti wafers, which measured $1 \times 1 \mathrm{~cm}$ (length $\mathrm{x}$ width), were obtained from the Center for Microtechnologies (ZFM, University of Technology Chemnitz, Germany). To sterilize the bare material, samples were incubated in $70 \%$ ethanol for 15 min and rinsed with phosphate buffer saline (PBS, Sigma Aldrich, Munich, Germany).

One of the modifications of the bare Ti substrate was the wet chemical coating with collagen type-I $(\mathrm{Ti}+\mathrm{Col})$. For this purpose, $200 \mu \mathrm{l}$ of a collagen work solution (Col, type I, rat tail tendon, BD Bioscience, Heidelberg, Germany, $200 \mu \mathrm{g} / \mathrm{ml}$ in acetic acid) was dripped onto the $\mathrm{Ti}$ sample under sterile conditions (laminar flow box) and allowed to adhere for $3 \mathrm{~h}$. To remove the acetic acid from the working solution, the surfaces were rinsed 3 times with PBS before use.

Another chemical modification of the bare Ti was the coating with plasma polymerized allylamine (PPAAm) $(\mathrm{Ti}+$ PPAAm). The preparation was carried out in a lowpressure microwave plasma reactor $(2.45 \mathrm{GHz} ; 500 \mathrm{~W}$, $50 \mathrm{~Pa})$ V55G (Plasma Finish, Germany, V=60 l). The samples underwent a two-step procedure: at first they were decontaminated and activated in pulsed oxygen plasma (10 ms on/90 ms off; $30 \mathrm{~s}$ effective) and then, without breaking the vacuum, coated with the monomer allylamine by the pulsed plasma polymerization process (300 ms on, $1700 \mathrm{~ms}$ off, $72 \mathrm{~s}$ effective, gross $480 \mathrm{~s}$ ). Prior to use, the allylamine was carefully purified of air by evacuating and purging with $\mathrm{N}_{2}$. A liquid handling system allowed for the exact dosing of allylamine. Argon was used as a carrier gas ( $50 \mathrm{sccm} \mathrm{Ar}$ ). The substrate was located in the plasma reactor in a downstream position [11]. The thickness of the deposited coatings was around $25 \mathrm{~nm}$. Before the experiments started, these surfaces were rinsed with PBS.

The following control surfaces were used for the experiments - a bare Ti wafer (see above) and a tissue culture plastic (IBIDI). The tissue culture plastic ibidi $\mu$-dishes with polymer coverslip (ibiTreat, Ø $35 \mathrm{~mm}$; ibidi $\mathrm{GmbH}$, Martinsried, Germany) are appropriate for microscopy and cell-based assays and fulfill optical requirements [29].

\section{Surface characterization-surface charge}

Zeta-potential measurements were performed using the SurPASS $^{\mathrm{TM}}$ system (Anton Paar, Ostfildern, Germany) to determine the surface charge. Smooth samples with a size of $2 \times 1 \mathrm{~cm}$ were mounted pairwise in the chamber with a gap height of $100 \mu \mathrm{m}$. The measurements were performed in a $0.001 \mathrm{~mol} / \mathrm{K} \mathrm{KCl}$ solution ranging from $\mathrm{pH} 6.0$ to 8.0. The streaming current was determined depending on the pressure (max. 400 mbar). Finally, the zeta potential was calculated according to the method of Helmholtz-Smoluchowski. Measurements were 
performed in quadruplicate on three independent pairs of samples (except for IBIDI, where only two samples were measured).

\section{Surface characterization-wettability}

The water contact angle (WCA) was determined by the sessile drop method using the Drop Shape AnalyzerDSA25 (Krüss GmbH, Hamburg, Germany) and $2 \mu \mathrm{l}$ distilled water. Drop images were acquired with the digital camera of the DSA25, and the contact angles were determined with the included software by the fit method ellipse (ADVANCE, V.1.7.2.1). The measurements were done with three sessile drops on one sample (technical triplicates), and 3 independent samples were used for each surface $(n=3)$.

\section{Cell culture}

For the main part of the experiments, MG-63 cells, a human osteoblast-like cell line from ATCC (American Type Culture Collection ATCC ${ }^{\circledR}, \mathrm{CRL}_{1427^{\mathrm{TM}}}$ ) were used. The MG-63 cell line has similar characteristics concerning morphological behavior, adhesion, integrin receptor expression and signaling properties to primary human osteoblasts [31]. For comparison and confirmation of the intracellular calcium ion dynamic we used human primary osteoblasts (HOB, PromoCell GmbH, Heidelberg, Germany, C-12720) as well. Both cell types were cultured at $37^{\circ} \mathrm{C}$ in a humidified atmosphere $\left(5 \% \mathrm{CO}_{2}\right)$. MG-63 cells were grown in Dulbecco's modified eagle medium (DMEM; Life Technologies GmbH, Darmstadt, Germany), with $10 \%$ fetal calf serum (FCS, Biochrom FCS Superior, Merck KGaA, Darmstadt, Germany) and $1 \%$ antibiotic (gentamicin, Ratiopharm GmbH, Ulm, Germany). Experiments were performed in passages 5-25. The HOB cells were cultivated in osteoblast growth medium with SupplementMix (PromoCell) and 1\% antibiotic-antimycotic (Anti-Anti 100×, Life Technologies). Investigations with $\mathrm{HOB}$ were done in low passages (two to four). All cell cultures were examined prior to further examination on the one hand for mycoplasma, and on the other hand for density and growth. Cells in the nearconfluent state (70-80\% of confluency) were used for the corresponding in vitro-experiments.

\section{Relative cell viability assay}

To estimate the relative viability of cells growing on different chemical surface compositions, MTS assay was used. MTS ((3-(4,5-dimethylthiazol-2-yl)-5-(3carboxymethoxyphenyl)-2-(4-sulfophenyl)-2 $\mathrm{H}$-tetrazolium salt), a yellow tetrazolium, is reduced to purple formazan in living cells by mitochondrial metabolic activity. The absorbance of this colored solution could be measured. For this, MG-63 cells (50,000 cells/ $\mathrm{cm}^{2}$ ) were seeded onto the $1 \times 1 \mathrm{~cm}$ surfaces in 24-well plates (Thermo Fisher Scientific, Roskilde, Denmark) and cultivated for $24 \mathrm{~h}$. Thereafter, materials with adherent cells were transferred into a fresh 24 -well plate. Here, cells were incubated for $2-3 \mathrm{~h}$ in $500 \mu \mathrm{l}$ culture medium containing $100 \mu \mathrm{l}$ of MTS reagent (CellTiter $96^{\circledR}$ Aqueous ONE-Solution Cell Proliferation Assay, Promega, USA) at $37^{\circ} \mathrm{C}$. Supernatants were transferred into a 96-well plate (for each experimental group $4 \times 100 \mu \mathrm{l}$ were analyzed). The absorbance was recorded at $490 \mathrm{~nm}$ with a microplate reader (Anthos, Mikrosysteme, Krefeld, Germany). A background measurement was taken at $650 \mathrm{~nm}$. To quantify the cell number, crystal violet staining was performed. Crystal violet binds to the negatively charged DNA in a linear fashion via ionic attraction. Staining was done on the basis of a protocol published previously [32]. Briefly, cells were fixed in 2-propanol (Walter CMP $\mathrm{GmbH}$, Kiel, Germany) after washing with PBS. The permeabilization of the cell membrane was achieved by washing with $0.05 \%$ Tween 20 (VWR Chemicals, Leuven, Belgium). After shaking with $0.1 \%$ crystal violet solution (Serva, Heidelberg, Germany) for $20 \mathrm{~min}$ at room temperature, cells were washed with double-distilled (dd) $\mathrm{H}_{2} \mathrm{O}$. The bound crystal violet was re-dissolved using 33\% acetic acid (J. T. Baker, Deventer, Netherlands). The optical density of the transferred supernatants was quantified with a microplate reader at $620 \mathrm{~nm}$. The relative cell viability of osteoblasts will be presented as a quotient of MTS and crystal violet data.

\section{Intracellular $\mathrm{Ca}^{2+}$ dynamic analysis by calcium imaging}

For the live cell calcium imaging, 80,000 cells $/ \mathrm{cm}^{2}$ osteoblasts were cultured on $1 \times 1 \mathrm{~cm}$ samples with different chemical compositions for $24 \mathrm{~h}$, and afterwards washed with pre-warmed PBS $(+\mathrm{Ca} / \mathrm{Mg}$, Sigma) and stained with the calcium indicator fluo-3/AM (Life Technologies Corporation, Eugene, Oregon, US, $5 \mu \mathrm{M}$ ) according to Staehlke et al. [10]. Briefly, cells were transferred to a slightly hypotonic 4-(2-hydroxyethyl)1-piperazineethanesulfonic acid (HEPES) buffer and loaded with fluo-3/AM. Fluo-3 is engineered with acetoxymethyl (AM) ester to load the dye into the osteoblasts [21]. In order to completely incorporate the dye in the osteoblasts for the best fluorescence signal, the method of hypo-osmotic shock treatment was additionally applied [16]. After incubation of the fluo-3/ AM $\left(40\right.$ min at $\left.37^{\circ} \mathrm{C}\right)$, the cells were cultured further in an isotonic HEPES buffer. Vital fluo-3/AM-labeled osteoblasts were visualized by a confocal laser scanning microscope (LSM780, Carl Zeiss AG, Oberkochen, Germany) with a C Apochromat $40 \times$ water immersion objective (Carl Zeiss, 1.20 W Korr M27) and an excitation at $488 \mathrm{~nm}$ by the argon ion laser (emission 
at $515 \mathrm{~nm})$. To record the global $\mathrm{Ca}^{2+}$ fluorescence signal from single cells, the mode "time series" of the ZEN software (ZEISS efficient navigation, ZEN 2011 SP4, black edition, Carl Zeiss) of one cycle every $2 \mathrm{~s}$ for 240 cycles was applied. In order to stimulate the intracellular $\mathrm{Ca}^{2+}$ release from the endoplasmic reticulum and thus the intracellular calcium dynamic, ATP (adenosine 50-triphosphate, $10 \mu \mathrm{M}$, SERVA Electrophoresis $\mathrm{GmbH}$, Heidelberg, Germany) was added to the experiment always at the same time point-after the 90th cycle-during the recording of the time series. At least three independent samples were analyzed for each experimental group to assess the chemical surface influence on the calcium ion dynamic. Samples were exposed with the same settings (Gain, Digital Offset) as well as with a pinhole of maximal airy units (15 AU, $13.5 \mu \mathrm{m}$ section). The measurement of the mean fluorescence intensity (MFI) of the global $\mathrm{Ca}^{2+}$ signal from the separate images of the time series was done by ZEN2 (blue edition, version 2.0.0.0, Carl Zeiss). Ten defined areas of cells (one area per cell) for each time point $(240$ cycles $=240$ time points $)$ were analyzed using the function "mean ROI" (mean region of interest). For this, the corresponding defined areas were selected in the first image of a time series and the software analyzed the mean fluorescence intensity (MFI) of these areas in each cycle (one cycle $=$ one image) of the entire time series (Fig. 4). Fluorescence images were acquired at a resolution of $512 \times 512$ pixels.

\section{Statistical evaluation}

The statistical evaluation was conducted at least three times in independent tests. Results for the in vitroinvestigations are expressed as mean \pm standard error of the mean (s.e.m.). For the relative cell viability, we used the Mann-Whitney U-test. For the intracellular $\mathrm{Ca}^{2+}$ dynamic experiments, a multiple $t$-test was done. Significant differences were reported as adjusted p-values $<0.05$ (two-sided). All statistical analyses were performed with GraphPad Prism7 software (GraphPad Software Inc., La Jolla, CA USA).

\footnotetext{
Abbreviations

AM: acetoxymethyl ester; ATCC: American type culture collection; ATP: adenosine triphosphate; $\mathrm{AU}$ : airy unit; $\mathrm{Ca}^{2+}$ : calcium ions; Col: collagen type-l; DMEM: Dulbecco's modified eagle medium; ER: endoplasmic reticulum; ECM: extracellular matrix; FACS: fluorescence-activated cell scanning; FCS: fetal calf serum; HEPES: 4-(2-hydroxyethyl)-1-piperazine-ethanesulfonic acid; HOB: human primary osteoblasts (PromoCell); ibidi: Integrated BioDiagnostics (tissue culture plastic); LSM: laser scanning microscope; MFI: mean fluorescence intensity; MTS: 3-(4,5-dimethylthiazol-2-yl)-5-(3-carboxymethoxyphenyl)-2-(4sulfophenyl)-2H-tetrazolium salt; PBS: phosphate buffered saline; PPAAm: plasma polymerized allylamine; s.e.m.: standard error of the mean; Si: silicon; Ti: titanium; WCA: water contact angle; ZEN: ZEISS efficient navigation.
}

\section{Authors' contributions}

SS conceived the study, participated in its design and drafted the manuscript. SS carried out cell culturing, collagen coating and the calcium experiments as well as statistical analyses. HR carried out the zeta potential analyses and statistics, drafted and revised the manuscript. PM carried out the investigation of cell viability and drafted the manuscript. MG examined the wettability and reviewed the manuscript. BF coated the titanium with the PPAAm-layer and drafted the manuscript. BN supervised the project, and formed the idea for the concept and critically revised the manuscript. All authors read and approved the final manuscript.

\section{Author details \\ ${ }^{1}$ Dept. of Cell Biology, University Medical Center Rostock, Schillingallee 69, 18057 Rostock, Germany. ${ }^{2}$ Leibniz-Institute for Plasma Science and Technol- ogy (INP), Felix-Hausdorff-Str. 2, 17489 Greifswald, Germany.}

\section{Acknowledgements}

We thank Norbert Zichner (Center for Microtechnologies ZFM, Chemnitz University of Technology, Germany) for the production of the Si-Ti-coated wafers.

\section{Competing interests}

The authors declare that they have no competing interests.

\section{Availability of data and materials}

The datasets generated and analysed during the current study are not publicly available due to their location on the local file server of an active directory of the University Medical Center Rostock (Rostock, Germany) but are available from the corresponding author on reasonable request.

\section{Consent for publication}

Not applicable.

\section{Ethics approval and consent to participate}

Not applicable.

\section{Funding}

We appreciate the financial support of the German Research Foundation (DFG) graduate school welisa (No. 1505/2) and the DFG ELAINE (No. 1270/1). $\mathrm{SS}$ is grateful to the KarriereWegeMentoring-Programme of the University Medical Center Rostock (European Social Fund for Germany and the state of Mecklenburg-Vorpommern, ESF/14-SM-A41-0005/15). HR is currently supported by the German Ministry of Education and Research (BMBF; FKZ 13GW0109D).

\section{Publisher's Note}

Springer Nature remains neutral with regard to jurisdictional claims in published maps and institutional affiliations.

Received: 27 November 2017 Accepted: 14 March 2018

Published online: 21 March 2018

\section{References}

1. Guo CL, Harris NC, Wijeratne SS, Frey EW, Kiang CH. Multiscale mechanobiology: mechanics at the molecular, cellular, and tissue levels. Cell Biosci. 2013;3(1):25. https://doi.org/10.1186/2045-3701-3-25.

2. Bacakova L, Filova E, Parizek M, Ruml T, Svorcik V. Modulation of cell adhesion, proliferation and differentiation on materials designed for body implants. Biotechnol Adv. 2011;29:739-67.

3. Sanz-Herrera JA, Reina-Romo E. Cell-biomaterial mechanical interaction in the framework of tissue engineering: insights, computational modeling and perspectives. Int J Mol Sci. 2011;12(11):8217-44. https:// doi.org/10.3390/ijms12118217.

4. Anselme K, Ponche A, Bigerelle M. Relative influence of surface topography and surface chemistry on cell response to bone implant materials. Part 2: biological aspects. Proc Inst Mech Eng H. 2010;224(12):1487-507. 
5. Ismail FS, Rohanizadeh R, Atwa S, Mason RS, Ruys AJ, Martin PJ, et al. The influence of surface chemistry and topography on the contact guidance of MG63 osteoblast cells. J Mater Sci Mater Med. 2007;18:705-14.

6. Petrie TA, Raynor JE, Reyes CD, Burns KL, Collard DM, García AJ. The effect of integrin-specific bioactive coatings on tissue healing and implant osseointegration. Biomaterials. 2008;29(19):2849-57. https://doi. org/10.1016/j.biomaterials.2008.03.036.

7. Moerke C, Rebl H, Finke B, Dubs M, Nestler P, Airoudj A, et al. Abrogated cell contact guidance on amino-functionalized microgrooves. ACS Appl Mater Interfaces. 2017;9(12):10461-71. https://doi.org/10.1021/ acsami.6b16430.

8. Finke B, Rebl H, Hempel F, Schäfer J, Liefeith K, Weltmann K-D, et al. Ageing of plasma-polymerised allylamine nanofilms and the maintenance of their cell adhesion capacity. Langmuir. 2014;30(46):13914-24. https://doi. org/10.1021/la5019778.

9. Rebl H, Finke B, Rychly J, Schröder K, Nebe JB. Positively charged material surfaces generated by plasma polymerized allylamine enhance vinculin mobility in vital human osteoblasts. Adv Biomat. 2010;12:356-64. https:// doi.org/10.1002/adem.200980070.

10. Staehlke S, Koertge A, Nebe B. Intracellular calcium dynamics in dependence on topographical features of titanium. Biomaterials. 2015;46:48-57. https://doi.org/10.1016/j.biomaterials.2014.12.016.

11. Finke B, Luethen F, Schroeder K, Mueller PD, Bergemann C, Frant $M$, et al. The effect of positively charged plasma polymerization on initial osteoblastic focal adhesion on titanium surfaces. Biomaterials 2007;28:4521-34.

12. Rebl H, Finke B, Schmidt J, Mohamad HS, Ihrke R, Helm CA, et al. Accelerated cell-surface interlocking on plasma polymer-modified porous ceramics. Mater Sci Eng C Mater Biol Appl. 2016;69:1116-24. https://doi. org/10.1016/j.msec.2016.08.016.

13. Pommerenke $H$, Schmidt $C$, Dürr F, Nebe B, Lüthen F, Müller $P$, et al. The mode of mechanical integrin stressing controls intracellular signaling in osteoblasts. J Bone Min Res. 2002;17(4):603-11.

14. Berridge MJ. Calcium signalling remodelling and disease. Biochem Soc Trans. 2012;40(2):297-309. https://doi.org/10.1042/BST20110766.

15. Labelle D, Jumarie C. Moreau R. Capacitative calcium entry and proliferation of human osteoblast-like MG-63 cells. Cell Prolif. 2007:40(6):866-84

16. Takahashi A, Camacho P, Lechleiter JD, Herman B. Measurement of intracellular calcium. Physiol Rev. 1999;79(4):1089-125.

17. Izquierdo JH, Bonilla-Abadía F, Cañas CA, Tobón GJ. Calcium, channels, intracellular signaling and autoimmunity. Reumatol Clin. 2014;10:43-7. https://doi.org/10.1016/j.reuma.2013.05.008.

18. Liedert A, Kaspar D, Blakytny R, Claes L, Ignatius A. Signal transduction pathways involved in mechanotransduction in bone cells. Biochem Biophys Res Commun. 2006;349(1):1-5.

19. Kim JM, Choi S, Kwack KH, Kim SY, Lee HW, Park K. G protein-coupled calcium-sensing receptor is a crucial mediator of MTA-induced biological activities. Biomaterials. 2017;127:107-16. https://doi.org/10.1016/j. biomaterials.2017.02.038

20. Whitaker M. Calcium microdomains and cell cycle control. Cell Calcium. 2006;40(5e6):585-92.

21. Paredes RM, Etzler JC, Watts LT, Zheng W, Lechleiter JD. Chemical calcium indicators. Methods. 2008;46(3):143-51. https://doi.org/10.1016/j. ymeth.2008.09.025

22. Avila G, Misch K, Galindo-Moreno P, Wang HL. Implant surface treatment using biomimetic agents. Implant Dent. 2009;18(1):17-26. https://doi. org/10.1097/ID.0b013e318192cb7d.

23. Nebe JB, Moerke C, Staehlke S, Finke B, Schnabelrauch M, Anselme $\mathrm{K}$, et al. Complex cell physiology on topographically and chemically designed material surfaces. Mater Sci Forum. 2017;879:78-83. https://doi. org/10.4028/www.scientific.net/MSF.879.78.

24. Ravenscroft-Chang MS, Stohlman JM, Molnar P, Natarajan A, Canavan $\mathrm{HE}$, Teliska M, et al. Altered calcium dynamics in cardiac cells grown on silanemodified surfaces. Biomaterials. 2010;31(4):602-7. https://doi. org/10.1016/j.biomaterials.2009.09.084.

25. Sverzut AT, Crippa GE, Morra M, de Oliveira PT, Beloti MM, Rosa AL. Effects of type I collagen coating on titanium osseointegration: histomorphometric, cellular and molecular analyses. Biomed Mater. 2012;7(3):035007. https://doi.org/10.1088/1748-6041/7/3/035007.

26. Nebe B, Lüthen F, Finke B, Bergemann C, Schröder K, Rychly J, et al. Improved initial osteoblast's functions on amino-functionalized titanium surfaces. Biomol Eng. 2007;24(5):447-54. https://doi.org/10.1016/j. bioeng.2007.07.004.

27. Schulz MC, Korn P, Stadlinger B, Range U, Möller S, Becher J, et al. Coating with artificial matrices from collagen and sulfated hyaluronan influences the osseointegration of dental implants. J Mater Sci Mater Med. 2014;25(1):247-58. https://doi.org/10.1007/s10856-013-5066-3.

28. Morra M, Cassinelli C, Cascardo G, Cahalan P, Cahalan L, Fini M, et al. Surface engineering of titanium by collagen immobilization. Surface characterization and in vitro and in vivo studies. Biomaterials. 2003;24(25):463954. https://doi.org/10.1016/S0142-9612(03)00360-0.

29. Lab on a Slide, Solutions for BioMicroscopy. Ibidi GmbH, Martinried, Germany. 2007. http://www.zenonbio.hu/catalogues/ibidi_catalog_01_07. pdf. p. 14-5. Accessed 19 Oct 2017.

30. Reyes CD, Petrie TA, Burns KL, Schwartz Z, Garcia AJ. Biomolecular surface coating to enhance orthopaedic tissue healing and integration. Biomaterials. 2007:28:3228-35.

31. Czekanska EM, Stoddart MJ, Ralphs JR, Richards RG, Hayes JS. A phenotypic comparison of osteoblast cell lines versus human primary osteoblasts for biomaterials testing. J Biomed Mater Res A. 2014;102(8):263643. https://doi.org/10.1002/jbm.a.34937.

32. Van Kooten TG, Klein CL, Wagner M, Kirkpatrick CJ. Focal adhesions and assessment of cytotoxicity. J Biomed Mater Res. 1999;46(1):33-43.

\section{Submit your next manuscript to BioMed Central and we will help you at every step:}

- We accept pre-submission inquiries

- Our selector tool helps you to find the most relevant journal

- We provide round the clock customer support

- Convenient online submission

- Thorough peer review

- Inclusion in PubMed and all major indexing services

- Maximum visibility for your research

Submit your manuscript at www.biomedcentral.com/submit 